\title{
Beneficial effects of multisensory and cognitive stimulation in institutionalized elderly: | 2-months follow-up
}

\author{
Liliane Dias E Dias de \\ Macedo' \\ Thaís Cristina Galdino De \\ Oliveira' \\ Fernanda Cabral Soares' \\ João Bento-Torres ${ }^{1,2}$ \\ Natáli Valim Oliver Bento- \\ Torres ${ }^{1,2}$ \\ Daniel Clive Anthony ${ }^{3}$ \\ Cristovam Wanderley \\ Picanço-Diniz'
}

'Laboratory of Investigations in Neurodegeneration and Infection, Institute of Biological Sciences, University Hospital João de Barros Barreto, Federal University of Pará, ${ }^{2}$ College of Physical Therapy and Occupational Therapy, Federal University of Para, Belem, Para, Brazil; 'Laboratory of Experimental Neuropathology, Department of Pharmacology, University of Oxford, Oxford, England, UK

Correspondence: Cristovam Wanderley Picanço-Diniz Hospital Universitário João de Barros Barreto, Laboratório de Investigações em Neurodegeneração e Infecção, Rua Dos Mundurucus 4487, Belém 66073005, Pará, Brazil

Tel/fax+5591320I 6756

Email cwpdiniz@gmail.com
This article was published in the following Dove Press journal:

Clinical Interventions in Aging

19 August 2015

Number of times this article has been viewed

Abstract: We previously demonstrated the beneficial effects of a multisensory and cognitive stimulation program, consisting of 48 sessions, twice a week, to improve the cognition of elderly subjects living either in long-term care institutions (institutionalized - I) or in communities with their families (noninstitutionalized - NI). In the present study, we evaluated these subjects after the end of the intervention and compared the rate of age-related cognitive decline of those living in an enriched community environment (NI group, $n=15,74.1 \pm 3.9$ years old) with those living in the impoverished environment of long-term care institutions (I group, $n=20,75.1 \pm 6.8$ years old). Both groups participated fully in our stimulation program. Over 1 year, we conducted revaluations at five time points ( 2 months, 4 months, 6 months, 8 months, and 12 months) after the completion of the intervention. Both elderly groups were evaluated with the mini-mental state examination and selected language tests. Progressive cognitive decline was observed in both groups over the period. Indeed, it took only 4-6 months after the end of the stimulation program for significant reductions in language test scores to become apparent. However, earlier reductions in test scores were mainly associated with I group, and linguistic prosody test scores were significantly affected by institutionalization and time, two variables that interacted and reduced these scores. Moreover, I group reduced the Montréal cognitive assessment battery language tests scores 4 months before NI group. It remains to be investigated what mechanisms may explain the earlier and more intense language losses in institutionalized elderly.

Keywords: age-related cognitive impairment, multisensory and cognitive stimulation, longterm care institutions, community living, language assessment

\section{Introduction}

Even in the presence of age-related cognitive decline, there is increasing evidence demonstrating that the aging brain still exhibits plasticity and that it may be possible to slow the rate of deterioration through stimulation programs. ${ }^{1,2}$ Whereas epidemiological studies have correlated physical and cognitive inactivity with a higher risk of age-related cognitive decline, ${ }^{3,4}$ an active lifestyle and intellectual enrichment may help prevent these losses in old age..$^{5-8}$ The Alzheimer's Association estimates that if the onset of Alzheimer's disease could be delayed by 5 years due to successful interventions, there would be a $50 \%$ decrease in Alzheimer's diagnoses. ${ }^{2}$

Consistent with the view that the decline in memory and language may be related to environmental impoverishment is the suggestion that decline may be aggravated after institutionalization. ${ }^{9,10}$ Institutionalization is associated with an impoverishedlike environment with reduced sensory-motor and cognitive stimulation, social interactions, and physical activity, all of which contribute to a sedentary lifestyle. ${ }^{9}$ Promoting the cognitive and multisensory stimulation, which is a nonpharmacological 
evidence-based intervention, may reduce intellectual decline in both demented ${ }^{11}$ and nondemented ${ }^{12}$ elderly. Indeed, from a number of studies reviewing the impact of aerobic and cognitive training on cognitive status of healthy and cognitively impaired older adults, ${ }^{1-5}$ it became apparent that aerobic and cognitive stimulation can achieve modest skill-specific gains in cognitively healthy aged people and seems to delay cognitive decline on mild-impaired elderly. For example, exercise seems to improve executive functions, attention, processing speed, learning, and memory, with increasing volumes of hippocampus, prefrontal cortex, and basal ganglia, whereas sedentary age-matched individuals undergo impairments in cognitive functions and decrease of volumes in those areas. ${ }^{6,7}$ Cognitive stimulation also improves learning and memory, ${ }^{8,9}$ attention, ${ }^{10}$ executive functions, ${ }^{11}$ and global cognition. ${ }^{2,12-19}$

However, it is unclear what and for how long, therapeutic or prophylactic intervention techniques are capable of reducing the rate of progression of senile cognitive decline. ${ }^{20}$ There is now an urgent need to evaluate potential interventions and the duration of their effects using efficient neuropsychological tests, with an emphasis on those that measure performance in executive functions, memory, attention, and information processing speed, all of which are affected by aging. ${ }^{20}$ Some effective stimulation programs have led to positive outcomes in both healthy ${ }^{21,22}$ and demented elderly subjects, ${ }^{23,24}$ but less is known about the duration of the beneficial effects once the intervention programs are completed. ${ }^{25-27}$

We previously demonstrated, in elderly subject groups, the influence of institutionalized (I) versus community living noninstitutionalized (NI) on the beneficial outcomes of a 48-session, twice a week, program of multisensory and cognitive stimulation. ${ }^{14}$ Indeed, before stimulation, I group showed on average lower scores than NI group in a number of tests including Boston naming, semantic verbal fluency (SVF), phonological verbal fluency (PVF), key concepts metaphors - explanation, direct speech acts (DSA) - alternatives, and emotional prosody. Cognitive and multisensory stimulation reduced progressively the language differences between I and NI groups, and after 48 sessions, no differences in language test scores were detected. Because I group showed lower performance on the language tests before the stimulation, the amount of language improvement after stimulation was higher in I group than in NI group.

In the present study, we estimate the decline of the same groups, as assessed by selected neuropsychological tests, to evaluate the influence of their lifestyles on the magnitude of their losses and the duration of the cognitive beneficial effects.

\section{Methods}

This study was approved and conducted under the supervision of the Research Ethics Committee of the University Hospital João de Barros Barreto (Protocol No 3955/09) for research involving human subjects. All subjects and subscribing institutions agreed to participate voluntarily and provided written consent. Participants were individuals aged 65 years or older with no history of head trauma, stroke, primary depression, or chronic alcoholism. All older participants were considered cognitively healthy with appropriate mini-mental state examination (MMSE) scores that were adjusted for education level with the following cut-off points: illiterate: 13; 1-7 years of schooling: 18 ; and $\geq 8$ years of schooling: $26{ }^{28,29}$ As described elsewhere, ${ }^{28}$ volunteers were divided into two groups, matched for age and years of education: (Group 1) noninstitutionalized (NI, $n=15,74.1 \pm 3.9$ years old, $6.7 \pm 3.5$ years of schooling), which included those who lived in communities with their families, and (Group 2) institutionalized (I, $\mathrm{n}=20,75.1 \pm 6.8$ years old, $4.5 \pm 4.4$ years of schooling), which included those who lived in long-term care institutions. On average, the length of institutionalization was $7.2 \pm 0.85$ years, and all long-term care institutions had similar internal rules and environmental conditions. The NI elderly lived in communities with one or more family members.

The present study was a longitudinal follow-up and compared the performance of each participant at the end of the intervention program with their respective performance at 2 months, 4 months, 6 months, 8 months, and 12 months after the stimulation program ended. It was developed at the Laboratory of Investigations in Neurodegeneration and Infection of the Institute of Biological Sciences at the University Hospital João de Barros Barreto in the city of Belém, Brazil. Thus, the aim of the present study was to investigate the influence of contrasting lifestyles on the rate of neuropsychological cognitive decline in elderly at the end of a 48-session intervention program of multisensory and cognitive stimulation, which has been described elsewhere. ${ }^{28}$

\section{Cognitive assessment}

On the same day, individuals received a $\mathrm{MMSE}^{29-31}$ and where then subject to language tests by trained investigators in an environment with adequate lighting and reduced noise conditions. As previously described, ${ }^{28}$ all participants in the I group had their neuropsychological tests performed in the environment of their own long-term care institutions in a quiet, well-lit room with similar physical conditions and without interruptions. The NI subjects were tested in public community social centers for the elderly. The test administrators were the 
same for all participants. They were not blinded to the subjects in the I group, as they were assessed in their own institution.

\section{Language assessment}

The procedures for language assessment were previously described. ${ }^{28,32}$ In brief, they included the following: the Boston naming test (shortened version) was administered and analyzed according to parameterized data for Brazil, ${ }^{33,34}$ adopting a cutoff equivalent to the correct naming of 12 of 15 possible figures; SVF and PVF tests were administered and computed using the following cutoffs: $<9$ points for illiterate individuals, $<12$ points for individuals with $1-7$ years of schooling, and $<13$ points for individuals with $\geq 8$ years of schooling ${ }^{35}$ oral narratives were elicited using a picture stimulus - the cookie theft picture from Boston Diagnosis Aphasia test using previously published criteria on the information content of the image, including the number of key concepts, narrative efficiency, number of units of information, the total number of words, and concision ratio (ratio of information units to the total number of words); ${ }^{36,37}$ the Montréal cognitive assessment (MoCA) was administered and measured in accordance with guidelines validated for the Brazilian population ${ }^{38,39}$ comprising the following tests: metaphors (explanation and alternatives), DSA, and indirect speech acts (ISA) (explanation and alternatives), linguistic and emotional prosody, and narrative discourse (partial retelling, total retelling, and full-text comprehension).

\section{Statistical analysis}

We compared two treatments (institutionalization and community living) and measured each elderly subject at five time points ( 2 months, 4 months, 6 months, 8 months, and 12 months) after the end of stimulation program for each neuropsychological test. To that end, we used repeated measures with two-way analysis of variance (ANOVA). We also used two-tailed $t$-tests to measure the possible intra- and intergroup differences.

\section{Results MMSE and language assessments}

As shown in Tables 1 and 2, there were significant reductions in neuropsychological language tests scores between the end of the intervention period and different time windows

Table I The mini-mental state examination and language tests scores after multisensory and cognitive intervention in the institutionalized group

\begin{tabular}{|c|c|c|c|c|c|c|}
\hline & After 48 sessions & $2 \mathrm{mo}$ & $4 \mathrm{mo}$ & $6 \mathrm{mo}$ & $8 \mathrm{mo}$ & $12 \mathrm{mo}$ \\
\hline Mini-mental state examination & $24.3 \pm 0.72$ & $23.8 \pm 0.87$ & $22.5 \pm 0.90$ & $21.7 \pm 0.89$ & $21.1 \pm 0.91$ & $20.7 \pm 0.98$ \\
\hline Boston naming test & $12.8 \pm 0.74$ & $12.2 \pm 0.80$ & $\mathrm{II} .4 \pm 0.73$ & $10.6 \pm 0.73$ & $|0.3 \pm 0.7|$ & $9.6 \pm 0.74 *$ \\
\hline Semantic verbal fluency & $|4| \pm 0.88$. & $13.3 \pm 0.77$ & $11.7 \pm 0.70$ & $10.9 \pm 0.85$ & $10.9 \pm 0.91$ & $9.7 \pm 0.90 * *, \Delta$ \\
\hline Phonological verbal fluency & $8.3 \pm 0.95$ & $7.8 \pm 0.83$ & $6.9 \pm 0.84$ & $5.9 \pm 0.79$ & $5.3 \pm 0.80$ & $4.9 \pm 0.75^{*}$ \\
\hline \multicolumn{7}{|l|}{ Test of narrative } \\
\hline Key concepts & $3.0 \pm 0.33$ & $2.8 \pm 0.31$ & $2.3 \pm 0.30$ & $1.9 \pm 0.33$ & $1.9 \pm 0.30$ & $1.6 \pm 0.32 *$ \\
\hline Narrative efficiency & $1.7 \pm 0.18$ & $1.6 \pm 0.17$ & $0.5 \pm 0.16$ & $0.6 \pm 0.16^{\square}$ & $0.6 \pm 0.16$ & $0.5 \pm 0.16^{\Delta \Delta}$ \\
\hline Information units & $3.1 \pm 0.38$ & $2.8 \pm 0.35$ & $2.4 \pm 0.35$ & $2.0 \pm 0.30$ & $1.9 \pm 0.35$ & $1.5 \pm 0.33^{*}$ \\
\hline Total number of words & $44.7 \pm 5.12$ & $43.2 \pm 4.30$ & $40.9 \pm 3.85$ & $37.0 \pm 3.72$ & $36.6 \pm 3.67$ & $35.2 \pm 3.74$ \\
\hline Concision & $0.06 \pm 0.00$ & $0.06 \pm 0.00$ & $0.05 \pm 0.00$ & $0.05 \pm 0.00$ & $0.04 \pm 0.00$ & $0.03 \pm 0.00 *$ \\
\hline \multicolumn{7}{|l|}{ MoCA battery } \\
\hline Metaphors (explanation) & $27.3 \pm 1.59$ & $26.6 \pm 1.58$ & $24.6 \pm 1.51$ & $21.6 \pm 1.52$ & $21.7 \pm 1.60$ & $20.1 \pm 1.59 *, \Delta$ \\
\hline Metaphors (alternatives) & $14.5 \pm 0.92$ & $14.1 \pm 0.92$ & $14.3 \pm 0.79$ & $11.8 \pm 0.88$ & II.I \pm 0.88 & $10.1 \pm 0.86 * *, \Delta$ \\
\hline Direct speech acts (explanation) & $14.5 \pm 0.65$ & $14.0 \pm 0.72$ & $12.4 \pm 0.74$ & $10.6 \pm 0.62^{\square \square, \bullet \bullet}$ & $9.6 \pm 0.65^{\circ \circ, \dagger \dagger}$ & $5.8 \pm 0.53^{* *, \Delta \Lambda, \diamond \diamond}$ \\
\hline Direct speech acts (alternatives) & $8.3 \pm 0.33$ & $7.9 \pm 0.39$ & $6.9 \pm 0.39$ & $6.2 \pm 0.4 I^{\square \square, \bullet}$ & $5.6 \pm 0.43^{\circ \circ, \dagger \dagger}$ & $5.6 \pm 0.53 * *, \Delta \Delta$ \\
\hline Indirect speech acts (explanation) & $17.2 \pm 0.49$ & $16.5 \pm 0.53$ & $14.7 \pm 0.53^{\times}$ & $13.9 \pm 0.5 \mid \square \square$ & $13.3 \pm 0.61^{\circ 0, \dagger \dagger}$ & $12.2 \pm 0.55^{* *, \Delta \Delta, \diamond}$ \\
\hline Indirect speech acts (alternatives) & $9.3 \pm 0.17$ & $8.8 \pm 0.23$ & $8.1 \pm 0.28$ & $7.7 \pm 0.35^{\square}$ & $7.5 \pm 0.34^{\circ}$ & $7.1 \pm 0.32 *, \Delta$ \\
\hline Emotional prosody & $6.7 \pm 0.50$ & $6.3 \pm 0.37$ & $5.7 \pm 0.41$ & $4.8 \pm 0.49 \square$ & $4.5 \pm 0.40^{\circ}$ & $4.6 \pm 0.43^{*}$ \\
\hline Linguistic prosody & $7.6 \pm 0.38$ & $7.1 \pm 0.46$ & $6.2 \pm 0.45$ & $6.0 \pm 0.45$ & $5.8 \pm 0.32^{\circ}$ & 5. I $\pm 0.4 I * *, \Delta$ \\
\hline Partial retelling & $12.2 \pm 0.78$ & $11.7 \pm 0.66$ & $10.4 \pm 0.64$ & $8.9 \pm 0.69 \square$ & $8.9 \pm 0.67^{\circ}$ & $8.4 \pm 0.73 * *, \Delta$ \\
\hline Total retelling & $9.2 \pm 0.54$ & $8.7 \pm 0.51$ & $7.4 \pm 0.47$ & $6.4 \pm 0.40^{\square \square, \bullet \bullet}$ & $6.1 \pm 0.42^{\circ \circ, \dagger \dagger}$ & $5.9 \pm 0.42 * *, \Delta \Delta$ \\
\hline Comprehension & $8.5 \pm 0.64$ & $8.1 \pm 0.58$ & $7.4 \pm 0.65$ & $6.0 \pm 0.62^{\square}$ & $5.5 \pm 0.60^{\circ \circ, \dagger}$ & $5.5 \pm 0.55^{* *, \Delta}$ \\
\hline
\end{tabular}

Notes: Average scores \pm standard error are shown for the end of intervention (after 48 sessions) and at 2 mo, 4 mo, 6 mo, 8 mo, and I2-mo follow-up. ${ }^{\times}$After 48 sessions

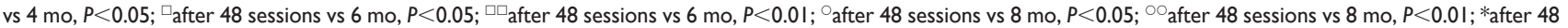

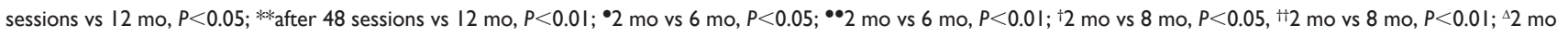

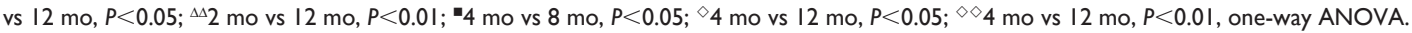

Abbreviations: mo, months; MoCA, Montréal cognitive assessment; ANOVA, analysis of variance. 
Table 2 The mini-mental state examination and language tests scores after multisensory and cognitive intervention in the noninstitutionalized group

\begin{tabular}{|c|c|c|c|c|c|c|}
\hline & After 48 sessions & $2 \mathrm{mo}$ & $4 \mathrm{mo}$ & $6 \mathrm{mo}$ & $8 \mathrm{mo}$ & $12 \mathrm{mo}$ \\
\hline Mini-mental state examination & $26.6 \pm 0.59$ & $26.3 \pm 0.55$ & $26.2 \pm 0.50$ & $24.3 \pm 0.55$ & $24.1 \pm 0.57^{\circ}$ & $23.9 \pm 0.58 * *, \Delta$ \\
\hline Boston naming test & $13.2 \pm 0.44$ & $13.3 \pm 0.38$ & $12.7 \pm 0.46$ & $12.6 \pm 0.54$ & $11.9 \pm 0.46$ & $|I .9 \pm 0.4|$ \\
\hline Semantic verbal fluency & $14.5 \pm 0.77$ & $14.4 \pm 0.66$ & $14.3 \pm 0.65$ & $13.1 \pm 0.59$ & $12.4 \pm 0.67$ & $11.7 \pm 0.68^{*}$ \\
\hline Phonological verbal fluency & $9.8 \pm 1.10$ & $9.7 \pm 1.10$ & $9.6 \pm 1.10$ & $8.3 \pm 1.00$ & $7.5 \pm 0.93$ & $6.8 \pm 0.75$ \\
\hline \multicolumn{7}{|l|}{ Narrative tests } \\
\hline Key concepts & $3.6 \pm 0.38$ & $3.5 \pm 0.30$ & $3.3 \pm 0.30$ & $2.9 \pm 0.29$ & $2.3 \pm 0.21^{\circ}$ & $2.3 \pm 0.25 *$ \\
\hline Narrative efficiency & $1.9 \pm 0.24$ & $1.8 \pm 0.20$ & $1.5 \pm 0.19$ & $1.3 \pm 0.18$ & $1.0 \pm 0.19^{\circ}$ & $1 . I \pm 0.18^{*}$ \\
\hline Information units & $3.5 \pm 0.32$ & $3.5 \pm 0.32$ & $3.1 \pm 0.28$ & $2.5 \pm 0.29$ & $2.1 \pm 0.23^{\circ, \dagger}$ & $2.1 \pm 0.23^{*, \Delta}$ \\
\hline Total number of words & $53.1 \pm 4.42$ & $50.5 \pm 3.73$ & $47.4 \pm 3.73$ & $48.9 \pm 3.37$ & $43.9 \pm 2.85$ & $43.0 \pm 3.20$ \\
\hline Concision & $0.07 \pm 0.00$ & $0.07 \pm 0.00$ & $0.07 \pm 0.00$ & $0.05 \pm 0.00$ & $0.05 \pm 0.00$ & $0.05 \pm 0.00$ \\
\hline \multicolumn{7}{|l|}{ MoCA battery } \\
\hline Metaphors (explanation) & $27.5 \pm 2.22$ & $28.7 \pm 2.19$ & $26.5 \pm 2.02$ & $27.1 \pm 1.97$ & $24.7 \pm 1.78$ & $22.9 \pm 1.86$ \\
\hline Metaphors (alternatives) & $16.0 \pm 1.06$ & $16.3 \pm 1.12$ & $\mid 5.1 \pm 1.20$ & $14.0 \pm 1.09$ & $|3.5 \pm 1.0|$ & $12.1 \pm 0.90$ \\
\hline Direct speech acts (explanation) & $13.1 \pm 0.98$ & $13.1 \pm 0.99$ & $12.9 \pm 0.97$ & $11.9 \pm 0.93$ & $10.6 \pm 0.77$ & $10.5 \pm 0.86$ \\
\hline Direct speech acts (alternatives) & $7.4 \pm 0.71$ & $8.0 \pm 0.51$ & $7.2 \pm 0.55$ & $6.1 \pm 0.63$ & $5.9 \pm 0.64$ & $5.5 \pm 0.47^{\Delta}$ \\
\hline Indirect speech acts (explanation) & $16.2 \pm 0.93$ & $15.7 \pm 0.89$ & $15.4 \pm 0.88$ & $13.9 \pm 0.77$ & $13.1 \pm 0.82$ & $12.2 \pm 0.72^{*, \Delta}$ \\
\hline Indirect speech acts (alternatives) & $9.3 \pm 0.25$ & $9.2 \pm 0.26$ & $8.7 \pm 0.27$ & $8.3 \pm 0.27$ & $7.9 \pm 0.2900, \dagger$ & $7.7 \pm 0.30 * *, \Delta \Delta$ \\
\hline Emotional prosody & $6.6 \pm 0.76$ & $6.9 \pm 0.65$ & $6.1 \pm 0.65$ & $4.7 \pm 0.55$ & $5.1 \pm 0.53$ & $4.9 \pm 0.46$ \\
\hline Linguistic prosody & $9.0 \pm 0.55$ & $8.9 \pm 0.63$ & $8.3 \pm 0.64$ & $7.6 \pm 0.72$ & $7.3 \pm 0.50$ & $6.9 \pm 0.52$ \\
\hline Partial retelling & $11.3 \pm 1.59$ & $11.6 \pm 1.27$ & $11.3 \pm 1.35$ & $10.1 \pm 1.28$ & $9.7 \pm 1.27$ & $8.9 \pm 1.11$ \\
\hline Total retelling & $9.2 \pm 0.84$ & $8.6 \pm 0.64$ & $8.1 \pm 0.7 \mid$ & $7.4 \pm 0.74$ & $6.8 \pm 0.60$ & $6.2 \pm 0.60 *$ \\
\hline Comprehension & $9.0 \pm 0.80$ & $8.0 \pm 0.70$ & $7.8 \pm 0.74$ & $7.5 \pm 0.68$ & $6.6 \pm 0.77$ & $6.8 \pm 0.61$ \\
\hline
\end{tabular}

Notes: Average scores \pm standard error are shown for the end of intervention (after 48 sessions) and at 2 mo, 4 mo, 6 mo, 8 mo, and I2-mo follow-up. ${ }^{\circ}$ After 48 sessions vs $8 \mathrm{mo}, P<0.05 ;{ }^{\circ}$ after 48 sessions vs $6 \mathrm{mo}, P<0.0$ I; *after 48 sessions vs $12 \mathrm{mo}, P<0.05 ; * *$ after 48 sessions vs $12 \mathrm{mo}, P<0.0 \mathrm{l},+2 \mathrm{mo}$ vs $8 \mathrm{mo}, P<0.05 ;{ }^{2} 2 \mathrm{mo}$ vs $12 \mathrm{mo}$, $P<0.05 ;{ }^{\Delta} 2$ mo vs 12 mo, $P<0.01$. One-way ANOVA.

Abbreviations: mo, months; MoCA, Montréal cognitive assessment; ANOVA, analysis of variance.

postintervention for both the I and NI groups. These reductions became apparent in I (Table 1) and NI (Table 2) groups after 4 months and 8 months, respectively. After 4 months, I group revealed significant decrease in the scores of ISA - explanation and 2 months later (6 months) in the scores of narrative efficiency, DSA - explanation and alternatives, ISA - explanation and alternatives, emotional prosody, partial and total retelling, and comprehension. After 8 months, the NI group showed significant decrease in the scores of MMSE, key concepts, narrative efficiency, information units, and ISA - alternatives. Twelve months after the end of the stimulation period, in the I group, the scores were significantly reduced in 18 of the language test scores (Table 1) compared with 8 scores in the NI group (Table 2). Although on average, the scores on the MMSE remained above cutoff points in both the I and NI groups at all time windows, there were no significant intragroup differences in the I group; whereas, the NI group started to show significant reduction in MMSE scores after 8 months.

Graphic representations of the mean scores \pm standard errors for the NI and I groups are shown in Figure 1, with significant differences between these groups indicated for each test, at each time point after the end of the intervention program. It is notable that all the significant differences, independent of the time window, revealed higher performances in the NI group compared with I group.

Repeated measurements with two-way ANOVA revealed a significant time influence on all language tests $(P<0.0001)$. Institutionalization significantly influenced $\operatorname{MMSE}(F=7.22$, $P=0.0112)$ and linguistic prosody $(F=5.95, P=0.0203)$ scores. There was a significant interaction between these variables (time and institutionalization) and linguistic prosody $(F=2.57, P=0.0201)$ scores (Figure 2). As compared with test scores before stimulation, the global cognition assessed by MMSE scores 12 months after the end of the stimulation program was preserved, but the linguistic prosody test scores were not in the I group.

Because statistical tests revealed interaction between institutionalization and time, and affect the results of linguistic prosody, we suggest that the impoverished environment of the long-term care institutions significantly reduced the beneficial effects of the intervention program on this language function.

However, many other language test scores revealed significant interactions between time and lifestyle (two-way 
A

MMSE

Boston naming test

Semantic verbal fluency
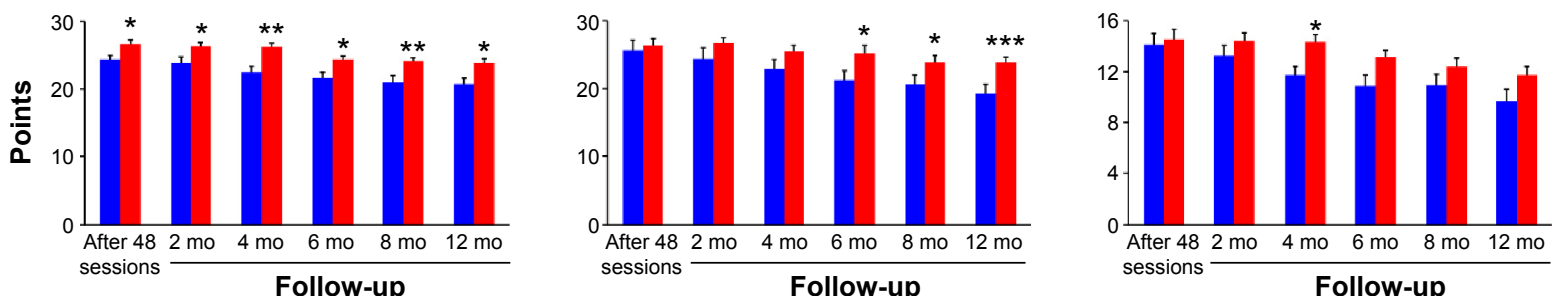

B

Key concepts

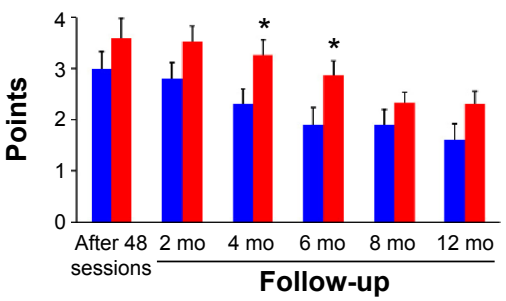

C

Total number of words

Follow-up
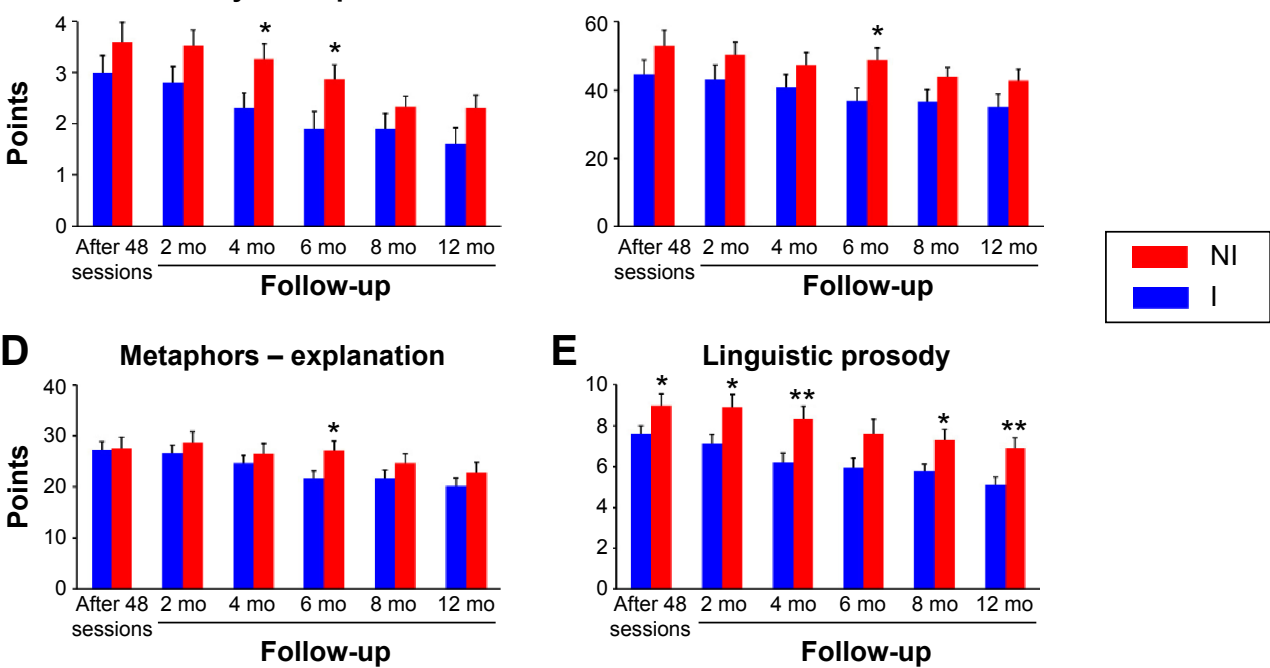

E

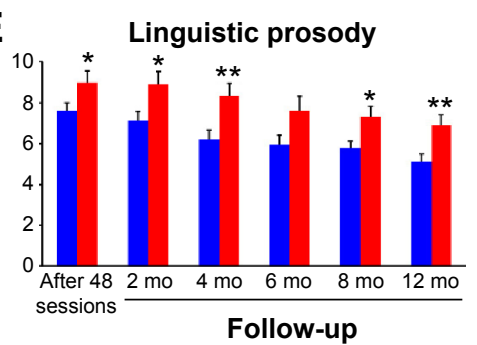

Figure I Graphical representations of the mean and standard errors of test scores on the MMSE and language tests in the institutionalized (blue bars) and noninstitutionalized (red bars) groups as a function of time.

Notes: (A) Test scores from the MMSE, Boston naming, and semantic verbal fluency. (B-E) Test scores from key concepts, total number of words, metaphors (explanation), and linguistic prosody. The columns represent the mean and the errors bars represent standard error values. The symbols $*, * *, * * *$ indicate $P$-values $=0.05,0.00 \mathrm{I}$, and $0.000 \mathrm{I}$ significant differences, respectively.

Abbreviations: MMSE, mini-mental state examination; mo, months; I, institutionalized; NI, noninstitutionalized.

A

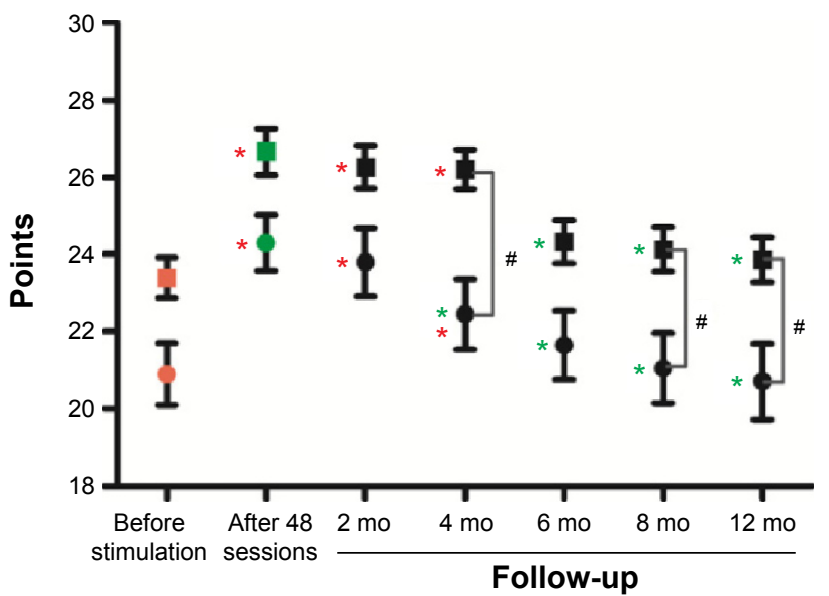

B

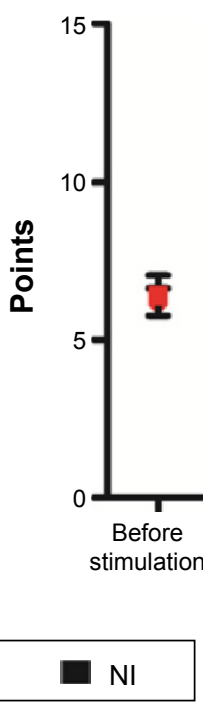

Linguistic prosody

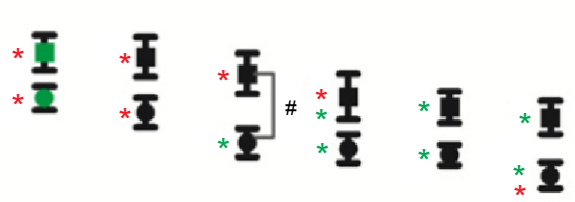

Figure 2 Graphical representations of the mean and standard error of tests scores in the institutionalized (circles) and noninstitutionalized (squares) groups as a function of time to illustrate the influence of time and institutionalization on (A) mini-mental state examination (MMSE) and (B) linguistic prosody test score reduction.

Notes: The mean is plotted and the standard errors are indicated by error bars. The colors and the position of the symbols indicate the comparisons that were significantly different.

Abbreviations: I, institutionalized; NI, noninstitutionalized; mo, months. 
ANOVA with repeated measurements), including DSA explanation, $P=0.0118$; DSA - alternatives, $P=0.0038$; ISA - explanations, $P=0.0038$; Boston naming, $P<0.0001$; SVF, $P=0.0040$; metaphors - explanation, $P=0.0008$; and comprehension, $P=0.0016$. These findings suggest that lifestyle may influence time effects on many other declining language functions.

Note that before intervention, the neuropsychological test scores from I group were significantly lower than NI group in both MMSE and a variety of language tests (Table 3), and after 48 sessions of multisensory and cognitive stimulation program, both I and NI groups could not be distinguished one from another based on those test results.

\section{Discussion}

To reduce age-related cognitive decline, the ageing brain must retain plasticity while maintaining the ability to change structurally or functionally, in a sustained way, when facing external stimuli. ${ }^{40}$ Thus, if multisensory and cognitive stimuli are reduced, age-related cognitive decline may increase., ${ }^{9,28}$ Using neuropsychological tests to assess language production and comprehension, we measured the influence of contrasting lifestyles on the duration of the beneficial effects of a 48-session, twice a week, multisensory and cognitive stimulation program. We found a progressive cognitive decline after the end of the stimulation program in both lifestyles (I and NI groups). However, elderly subjects living with their families in an enriched community environment showed delayed and smaller rates of cognitive decline than elderly subjects living outside their families in the impoverished environment of long-term care institutions.

It was previously described that sedentary and lone living in long-term care institutions for the elderly exhibit poorer cognitive functioning and show faster cognitive decline than physically and socially active people (for recent review, see Volkers and Scherder ${ }^{9}$ ). In addition, recent results described by Gonzalez-Colaço Harmand et al suggested that institutionalized, lone-living, elderly subjects show greater cognitive decline compared with elderly subjects living in the community with their families. ${ }^{41}$ These authors demonstrated, after following participants for 22 years, that after controlling for numerous potential confounders, nursing home placement was significantly associated with a lower score on the MMSE and further cognitive decline, when comparing

Table 3 Cognitive scores on MMSE and language tests before stimulation workshops in institutionalized (I) and noninstitutionalized (NI) elderly

\begin{tabular}{|c|c|c|c|c|}
\hline & \multicolumn{2}{|c|}{ Before stimulation } & \multirow[t]{2}{*}{ t-values } & \multirow[t]{2}{*}{$P$-values } \\
\hline & $\mathbf{I}$ & NI & & \\
\hline MMSE & $20.70 \pm 0.8$ & $23.4 \pm 0.5$ & MW & 0.0157 \\
\hline Boston naming & $10.8 \pm 0.5$ & $12.2 \pm 0.4$ & -2.0953 & 0.0441 \\
\hline Semantic verbal fluency & $10.2 \pm 0.7$ & $12.2 \pm 0.6$ & MW & 0.0514 \\
\hline Phonologic verbal fluency & $4.3 \pm 0.5$ & $6.9 \pm 0.8$ & -2.8077 & 0.0084 \\
\hline \multicolumn{5}{|l|}{ Narrative tests } \\
\hline Main concepts & $2.0 \pm 0.4$ & $3.2 \pm 0.3$ & MW & 0.0278 \\
\hline Narrative efficiency & $1.0 \pm 0.2$ & $1.7 \pm 0.2$ & -2.47 & 0.0188 \\
\hline Information units & $2.2 \pm 0.4$ & $2.9 \pm 0.4$ & -1.2783 & 0.2100 \\
\hline Total number of words & $38.7 \pm 5.0$ & $51.9 \pm 5.9$ & -1.7093 & 0.097 \\
\hline Concision rate & $0.05 \pm 0.01$ & $0.07 \pm 0.01$ & $-1.27 \mid 4$ & 0.2124 \\
\hline \multicolumn{5}{|l|}{ MoCA battery } \\
\hline Metaphors (explanation) & $18.1 \pm 1.9$ & $21.7 \pm 2.0$ & -1.2845 & 0.2078 \\
\hline Metaphors (alternatives) & $11.7 \pm 1.2$ & $13.3 \pm 1.2$ & -0.9757 & 0.3363 \\
\hline Direct speech acts (explanation) & $8.8 \pm 0.9$ & $10.7 \pm 0.7$ & -1.6259 & 0.1134 \\
\hline Direct speech acts (alternatives) & $6.1 \pm 0.7$ & $7.7 \pm 0.8$ & -1.5197 & 0.138 \\
\hline Indirect speech acts (explanation) & $11.9 \pm 0.7$ & $13.6 \pm 0.9$ & -1.4334 & 0.1614 \\
\hline Indirect speech acts (alternatives) & $8.3 \pm 0.3$ & $8.5 \pm 0.4$ & -0.3944 & 0.6959 \\
\hline Emotional prosody & $4.2 \pm 0.4$ & $5.0 \pm 0.3$ & -1.5734 & 0.1251 \\
\hline Linguistic prosody & $5.9 \pm 0.5$ & $6.4 \pm 0.6$ & -0.5985 & 0.5536 \\
\hline Partial retelling & $8.0 \pm 0.8$ & $10.3 \pm 1.2$ & -1.6421 & 0.11 \\
\hline Integral retelling & $6.1 \pm 0.6$ & $7.0 \pm 0.6$ & -1.07 & 0.2923 \\
\hline Comprehension & $6.1 \pm 0.8$ & $8.1 \pm 0.7$ & $-|.76| \mid$ & 0.0874 \\
\hline
\end{tabular}

Notes: Mean \pm standard errors and $P$-values to indicate statistical significant differences between groups are exhibited. MW indicates nonparametric Mann-Whitney U-tests.

Abbreviations: MMSE, mini-mental state examination; MoCA, Montréal cognitive assessment. 
scores before and after institutionalization. Regarding language abilities, a previous report ${ }^{42}$ demonstrated that naming function was maintained among day-care patients in comparison to institutionalized patients, who displayed reduced performance at follow-up. Similar tendencies of cognitive decline were described in Brazilian samples of institutionalized persons ${ }^{43,44}$ without regular activities, who had lower scores on the $\mathrm{MMSE}^{43}$ or the MMSE and Boston naming test when compared with institutionalized active and noninstitutionalized groups. ${ }^{44}$

However, data obtained previously in healthy aging subjects $^{28}$ and findings from other studies in both healthy and demented elderly subjects demonstrated that it is possible to improve cognitive $\mathrm{e}^{2,45-47}$ and perceptual ${ }^{48-51}$ functions through the training and exercises that make up the sensory/motor and cognitive-oriented stimulation programs for the elderly. The majority of these studies that have conducted interventions on older adults have focused on teaching some type of cognitive skills through practice and measuring improvement at the end of a training period.

In line with a previous report, ${ }^{28}$ we described the beneficial effects of 48 sessions of multisensory and cognitive stimulation based on language and memory exercises, as well as visual, olfactory, auditory, and ludic stimulation. At the end of that intervention program, we investigated in the same groups of volunteers how long those beneficial effects remained. Note that before stimulation, statistical differences between the average MMSE scores were not significant, whereas in the language tests a number of significant differences were detected. Indeed I group showed average significant lower scores than NI group in a number of tests, including Boston naming, SVF, and PVF; key concepts; metaphors - explanation; DSA - alternatives; and emotional prosody. After cognitive and multisensory stimulation, the language differences between I and NI groups were limited to PVF after 24 sessions, and after 48 sessions, no language differences were detected anymore. Because all significant differences between I and NI test scores found before stimulation disappeared after 48 sessions, we suggest that both I and NI groups were on average cognitively intact before we start the subsequent period of deprivation. However, after the end of stimulation period both I and NI individuals had their neuropsychological test scores significantly altered as a function of time, in different degrees. Indeed, it became clear from our findings that it took only 4-6 months after the end of the stimulation program for significant reductions in language test scores to become apparent. These score reductions started at different time windows and progressed at different rates for different language functions. Significant reductions in the language tests scores started earlier and affected a higher number of language functions; in addition, score reductions progressed faster in the I group than the NI group. The I group language test scores show significant decline in 18 different measurements (eleven scores from the MoCA battery test, four from the narrative measurements, Boston naming, SVF, and PVF tests); whereas, the NI group showed significant scores decline in only eight tests (four from the MoCA battery test, three from narrative measurements and SVF tests). These findings are in line with a previous report ${ }^{52}$ showing that the MoCA battery test may be a better detector of age-related decrements in cognitive performance than the MMSE. Indeed, all MMSE scores remained, on average, above the cutoff points at all time-windows poststimulation, there were no significant changes in the MMSE scores over time in the I group, but there was a significant change in the NI group after 8 months.

In addition, the I group started to show significant reductions in language test scores 4 months before the NI group. Consistently earlier reductions in test scores were mainly associated with the MoCA battery language tests for the I group, and linguistic prosody test scores were significantly affected by institutionalization and time, two variables that interacted and reduced these scores. In addition, the scores of many other language tests from the MoCA battery tests were significantly influenced by length of time after the intervention program ended, with significant interactions between time and institutionalization. These tests included comprehension, partial retelling, ISA - explanation, ISA alternatives, DSA - alternatives, DSA - explanations, and metaphors - explanation, suggesting that institutionalization may aggravate score reduction as a function of time for these tests. Similar results were found for SVF and Boston naming.

It is unclear why certain language test scores were more readily affected by institutionalization and time than others. Test scores are usually influenced by age and education, ${ }^{53}$ and these were similar in both groups; thus, it is feasible that the impoverished environment of the long-term care institutions and time affected the language functions that were less stimulated during the intervention workshops. The workshops stimulated the language functions assessed by the MoCA battery tests similarly to other language functions (Table S2 from De Oliveira et $\mathrm{a}^{28}$ ); therefore, we suggest that the language MoCA battery tests are more efficient than other tests at detecting earlier more subtle decline. We tested this hypothesis using receiver operating characteristic (ROC) analysis 
(data not shown). We determined tests with efficiencies $\geq 70 \%$ $(\text { efficiency }=[(\text { specificity }+ \text { sensitivity }) / 2])^{54}$ would detect subtle but significant cognitive declines earlier than tests with lower efficiencies. Indeed, the efficiency values of the MoCA tests were $>70 \% 4$ months after the end of the intervention in the I group; whereas the majority of the other language tests reached this level of efficiency only after 6 months. In addition, the MoCA battery tests include executive functions that are significantly impaired by aging, ${ }^{55,56}$ therefore, we suggest that the MoCA battery tests would detect the detrimental influence of the impoverished environment of long-term care institutions earlier than the other language tests would. Consistent with this, 6 months after the end of the intervention, scores on eight of eleven MoCA battery tests significantly declined in the I group, whereas scores declined on only one of the nine other language tests.

Another important finding was that NI elderly subjects showed less of a decline in neuropsychological language test scores than I subjects after the end of our interventional program. Thus, it is likely that the enriched environment interactions and socialization in the community lifestyles of the NI group exposed these subjects to greater cognitive and multisensory stimulation, sustaining the beneficial effects of the intervention program for a longer period compared to the I group.

However, important limitations should be considered when analyzing the results of the present study. For example, the sample size is relatively small, with 15 individuals in the NI group and 20 in the I group. In addition, our samples were matched for age and education, but not for comorbidities, medication, and genre. Thus, considering the potential variations of physical health conditions and initial cognitive abilities, the two groups may not be well controlled to exclude all possible cofound factors. For example, although the two groups showed similar MMSE scores after the intervention period, they showed significant differences before the stimulation program, with a higher MMSE score in the NI group than the I group. Because NI group had better learning and memory abilities before intervention, they could better maintain the training effect. However, since there was no comparison with a "no intervention" control group, it is impossible to distinguish the influence of a practice effect on the results.

Thus, with the limitations previously indicated, this study shows that the magnitude and duration of the benefits acquired from stimulation paradigms for the elderly are significantly different in institutionalized and noninstitutionalized elderly and that this ought to be considered in the development of more effective intervention programs.

\section{Acknowledgment}

This work was supported by Programa Pesquisa para o SUS: gestão compartilhada em saúde (PPSUS) - Ministério da Saúde/Conselho Nacional de Desenvolvimento Científico e Tecnológico (CNPq)/Fundação de Amparo à Pesquisa do Estado do Pará (FAPESPA)/Secretaria de Saúde do Estado do Pará (SESPA) (Grant Nos 051/2007 and 013/2009), Agência Brasileira da Inovação (FINEP)/Fundação de Amparo e Desenvolvimento da Pesquisa (FADESP) (Grant No 01.04.0043.00), and Pró-Reitoria de Pesquisa (PROPESPUFPA)/Fundação de Amparo e Desenvolvimento da Pesquisa (FADESP).

\section{Authors' contribution}

All authors contributed toward data analysis, drafting and revising the paper and agree to be accountable for all aspects of the work.

\section{Disclosure}

The authors report no conflicts of interest in this work.

\section{References}

1. Mora F. Successful brain aging: plasticity, environmental enrichment, and lifestyle. Dialogues Clin Neurosci. 2013;15(1):45-52.

2. Park DC, Bischof GN. The aging mind: neuroplasticity in response to cognitive training. Dialogues Clin Neurosci. 2013;15(1):109-119.

3. Tyndall AV, Davenport MH, Wilson BJ, et al. The brain-in-motion study: effect of a 6-month aerobic exercise intervention on cerebrovascular regulation and cognitive function in older adults. BMC Geriatr. 2013;13:21.

4. Erickson KI, Weinstein AM, Lopez OL. Physical activity, brain plasticity, and Alzheimer's disease. Arch Med Res. 2012;43(8):615-621.

5. Small BJ, Dixon RA, McArdle JJ, Grimm KJ. Do changes in lifestyle engagement moderate cognitive decline in normal aging? Evidence from the Victoria Longitudinal Study. Neuropsychology. 2012; 26(2):144-155.

6. Lovden M, Xu W, Wang HX. Lifestyle change and the prevention of cognitive decline and dementia: what is the evidence? Curr Opin Psychiatry. 2013;26(3):239-243.

7. Pope SK, Shue VM, Beck C. Will a healthy lifestyle help prevent Alzheimer's disease? Annu Rev Public Health. 2003;24:111-132.

8. Vemuri P, Lesnick TG, Przybelski SA, et al. Association of lifetime intellectual enrichment with cognitive decline in the older population. JAMA Neurol. 2014;71(8):1017-1024.

9. Volkers KM, Scherder EJ. Impoverished environment, cognition, aging and dementia. Rev Neurosci. 2011;22(3):259-266.

10. Zalik E, Zalar B. Differences in mood between elderly persons living in different residential environments in Slovenia. Psychiatr Danub. 2013;25(1):40-48.

11. Aguirre E, Woods RT, Spector A, Orrell M. Cognitive stimulation for dementia: a systematic review of the evidence of effectiveness from randomised controlled trials. Ageing Res Rev. 2013;12(1):253-262.

12. Reijnders J, van Heugten C, van Boxtel M. Cognitive interventions in healthy older adults and people with mild cognitive impairment: a systematic review. Ageing Res Rev. 2013;12(1):263-275.

13. Kelly ME, Loughrey D, Lawlor BA, Robertson IH, Walsh C, Brennan S. The impact of cognitive training and mental stimulation on cognitive and everyday functioning of healthy older adults: a systematic review and meta-analysis. Ageing Res Rev. 2014;15:28-43. 
14. Pieramico V, Esposito R, Cesinaro S, Frazzini V, Sensi SL. Effects of non-pharmacological or pharmacological interventions on cognition and brain plasticity of aging individuals. Front Syst Neurosci. 2014;8:153.

15. Tardif S, Simard M. Cognitive stimulation programs in healthy elderly: a review. Int J Alzheimers Dis. 2011;2011:378934.

16. Kurz AF, Leucht S, Lautenschlager NT. The clinical significance of cognition-focused interventions for cognitively impaired older adults: a systematic review of randomized controlled trials. Int Psychogeriatr 2011;23(9):1364-1375.

17. Rebok GW, Carlson MC, Langbaum JB. Training and maintaining memory abilities in healthy older adults: traditional and novel approaches. J Gerontol B Psychol Sci Soc Sci. 2007;62(Spec No 1):53-61.

18. Erickson KI, Voss MW, Prakash RS, et al. Exercise training increases size of hippocampus and improves memory. Proc Natl Acad Sci US A. 2011 108(7):3017-3022.

19. Erickson KI, Prakash RS, Voss MW, et al. Brain-derived neurotrophic factor is associated with age-related decline in hippocampal volume. J Neurosci. 2010;30(15):5368-5375.

20. Alexander GE, Ryan L, Bowers D, et al. Characterizing cognitive aging in humans with links to animal models. Front Aging Neurosci. 2012;4:21.

21. Verhaeghen P, Marcoen A, Goossens L. Improving memory performance in the aged through mnemonic training: a meta-analytic study. Psychol Aging. 1992;7(2):242-251.

22. Ball K, Berch DB, Helmers KF, et al; Advanced Cognitive Training for Independent and Vital Elderly Study Group. Effects of cognitive training interventions with older adults: a randomized controlled trial. JAMA. 2002;288(18):2271-2281.

23. Cove J, Jacobi N, Donovan H, Orrell M, Stott J, Spector A. Effectiveness of weekly cognitive stimulation therapy for people with dementia and the additional impact of enhancing cognitive stimulation therapy with a carer training program. Clin Interv Aging. 2014;9:2143-2150.

24. Yates LA, Leung P, Orgeta V, Spector A, Orrell M. The development of individual cognitive stimulation therapy (iCST) for dementia. Clin Interv Aging. 2015;10:95-104.

25. Willis SL, Tennstedt SL, Marsiske M, et al; ACTIVE Study Group Long-term effects of cognitive training on everyday functional outcomes in older adults. JAMA. 2006;296(23):2805-2814.

26. La Rue A. Healthy brain aging: role of cognitive reserve, cognitive stimulation, and cognitive exercises. Clin Geriatr Med. 2010;26(1):99-111.

27. Mahncke HW, Connor BB, Appelman J, et al. Memory enhancemen in healthy older adults using a brain plasticity-based training program: a randomized, controlled study. Proc Natl Acad Sci US A. 2006;103(33): 12523-12528.

28. De Oliveira TC, Soares FC, De Macedo LD, Diniz DL, Bento-Torres NV, Picanço-Diniz CW. Beneficial effects of multisensory and cognitive stimulation on age-related cognitive decline in long-term-care institutions. Clin Interv Aging. 2014;9:309-320.

29. Bertolucci PH, Brucki SM, Campacci SR, Juliano Y. O Mini-Exame do Estado Mental em uma população geral: impacto da escolaridade [The mini-mental state examination in a general population: impact of educational status]. Arq Neuropsiquiatr. 1994;52(1):1-7.

30. Folstein MF, Folstein SE, McHugh PR. "Mini-mental state". A practical method for grading the cognitive state of patients for the clinician. J Psychiatr Res. 1975;12(3):189-198.

31. Marcopulos B, McLain C. Are our norms "normal"? A 4-year follow-up study of a biracial sample of rural elders with low education. Clin Neuropsychol. 2003;17(1):19-33.

32. Soares FC, de Oliveira TC, de Macedo LD, et al. CANTAB object recognition and language tests to detect aging cognitive decline: an exploratory comparative study. Clin Interv Aging. 2015; 10:37-48.

33. Bertolucci PHF, Okamoto IH, Toniolo JN, Ramos LR, Bruki SMD. Desempenho da população brasileira na bateria neuropsicológica do consortium to establish a registry for Alzheimer's Disease (CERAD). Revista Psiquiatria Clínica. 1998;25:80-83.

34. Bertolucci PH, Okamoto IH, Brucki SM, Siviero MO, Toniolo Neto J, Ramos LR. Applicability of the CERAD neuropsychological battery to Brazilian elderly. Arq Neuropsiquiatr. 2001;59(3-A):532-536.
35. Caramelli P, Carthery-Goulart MT, Porto CS, Charchat-Fichman H, Nitrini R. Category fluency as a screening test for Alzheimer disease in illiterate and literate patients. Alzheimer Dis Assoc Disord. 2007; 21(1):65-67.

36. Forbes-McKay KE, Venneri A. Detecting subtle spontaneous language decline in early Alzheimer's disease with a picture description task. Neurol Sci. 2005;26(4):243-254.

37. Groves-Wright K, Neils-Strunjas J, Burnett R, O’Neill MJ. A comparison of verbal and written language in Alzheimer's disease. J Commun Disord. 2004;37(2):109-130.

38. Fonseca RP, Joanette Y, Côté H, et al. Brazilian version of the Protocole Montreal d'Evaluation de la Communication (Protocole MEC) normative and reliability data. Span J Psychol. 2008;11(2):678-688.

39. Fonseca RP, Parente MA, Côté H, Ska B, Joanette Y. Introducing a communication assessment tool to Brazilian speech therapists: the MAC Battery. Pro Fono. 2008;20(4):285-291.

40. Winocur G. Environmental influences on cognitive decline in aged rats. Neurobiol Aging. 1998;19(6):589-597.

41. González-Colaço Harmand M, Meillon C, Rullier L, et al. Cognitive decline after entering a nursing home: a 22-year follow-up study of institutionalized and noninstitutionalized elderly people. $\mathrm{J} \mathrm{Am} \mathrm{Med}$ Dir Assoc. 2014;15(7):504-508

42. Maseda A, Balo A, Lorenzo-López L, Lodeiro-Fernández L, RodríguezVillamil JL, Millán-Calenti JC. Cognitive and affective assessment in day care versus institutionalized elderly patients: a 1-year longitudinal study. Clin Interv Aging. 2014;9:887-894.

43. Medeiros de A Nunes V, Alchieri JC, Azevedo LM, Varela de Oliveira KM, Pereira DA. Cognitive assessment in elderly residents of long-stay institutions. Dement Geriatr Cogn Disord. 2014;37(1-2):27-33.

44. Plati MC, Covre P, Lukasova K, de Macedo EC. Depressive symptoms and cognitive performance of the elderly: relationship between institutionalization and activity programs. Rev Bras Psiquiatr. 2006;28(2): $118-121$.

45. Fitzsimmons S, Buettner LL. Therapeutic recreation interventions for need-driven dementia-compromised behaviors in community-dwelling elders. Am J Alzheimers Dis Other Demen. 2002;17(6):367-381.

46. Cheng ST, Chow PK, Song YQ, et al. Mental and physical activities delay cognitive decline in older persons with dementia. Am J Geriatr Psychiatry. 2014;22(1):63-74.

47. Ruthirakuhan M, Luedke AC, Tam A, Goel A, Kurji A, Garcia A. Use of physical and intellectual activities and socialization in the management of cognitive decline of aging and in dementia: a review. J Aging Res. 2012;2012:384875.

48. Legault I, Faubert J. Perceptual-cognitive training improves biological motion perception: evidence for transferability of training in healthy aging. Neuroreport. 2012;23(8):469-473.

49. Legault I, Allard R, Faubert J. Healthy older observers show equivalent perceptual-cognitive training benefits to young adults for multiple object tracking. Front Psychol. 2013;4:323.

50. Bower JD, Andersen GJ. Aging, perceptual learning, and changes in efficiency of motion processing. Vision Res. 2012;61:144-156.

51. Bower JD, Watanabe T, Andersen GJ. Perceptual learning and aging: improved performance for low-contrast motion discrimination. Front Psychol. 2013;4:66.

52. Gluhm S, Goldstein J, Loc K, Colt A, Liew CV, Corey-Bloom J. Cognitive performance on the mini-mental state examination and the montreal cognitive assessment across the healthy adult lifespan. Cogn Behav Neurol. 2013;26(1):1-5.

53. Freitas S, Simões MR, Alves L, Santana I. Montreal Cognitive Assessment: influence of sociodemographic and health variables. Arch Clin Neuropsychol. 2012;27(2):165-175

54. Fawcet T. An introduction to ROC analysis. Pattern Recognit Lett. 2006;27:861-874.

55. Mitchell RL, Kingston RA, Barbosa Bouças SL. The specificity of age-related decline in interpretation of emotion cues from prosody. Psychol Aging. 2011;26(2):406-414.

56. Kiss I, Ennis T. Age-related decline in perception of prosodic affect. Appl Neuropsychol. 2001;8(4):251-254. 


\section{Publish your work in this journal}

Clinical Interventions in Aging is an international, peer-reviewed journal focusing on evidence-based reports on the value or lack thereof of treatments intended to prevent or delay the onset of maladaptive correlates of aging in human beings. This journal is indexed on PubMed Central, MedLine,

CAS, Scopus and the Elsevier Bibliographic databases. The manuscript management system is completely online and includes a very quick and fair peer-review system, which is all easy to use. Visit http://www.dovepress. com/testimonials.php to read real quotes from published authors. 